\title{
Ex vivo tissue slice culture system to measure drug-response rates of hepatic metastatic colorectal cancer
}

\author{
Steve Z. Martin ${ }^{1,2^{*}}$ D, Daniel C. Wagner ${ }^{1}$, Nina Hörner ${ }^{1}$, David Horst ${ }^{2}$, Hauke Lang ${ }^{3}$, Katrin E. Tagscherer ${ }^{1}$ and
} Wilfried Roth ${ }^{1}$

\begin{abstract}
Background: The lack of predictive biomarkers or test systems contributes to high failure rates of systemic therapy in metastasized colorectal carcinoma, accounting for a still unfavorable prognosis. Here, we present an ex vivo functional assay to measure drug-response based on a tissue slice culture approach.

Methods: Tumor tissue slices of hepatic metastases of nine patients suffering from colorectal carcinoma were cultivated for $72 \mathrm{~h}$ and treated with different concentrations of the clinically relevant drugs Oxaliplatin, Cetuximab and Pembrolizumab. Easy to use, objective and automated analysis routines based on the Halo platform were developed to measure changes in proliferative activity and the morphometric make-up of the tumor. Apoptotic indices were assessed semiquantitatively.

Results: Untreated tumor tissue slices showed high morphological comparability with the original "in vivo"-tumor, preserving proliferation and stromal-tumor interactions. All but one patients showed a dosage dependent susceptibility to treatment with Oxaliplatin, whereas only two patients showed responses to Cetuximab and Pembrolizumab, respectively. Furthermore, we identified possible non-responders to Cetuximab therapy in absence of RAS-mutations.

Conclusions: This is the first time to demonstrate feasibility of the tissue slice culture approach for metastatic tissue of colorectal carcinoma. An automated readout of proliferation and tumor-morphometry allows for quantification of drug susceptibility. This strongly indicates a potential value of this technique as a patient-specific test-system of targeted therapy in metastatic colorectal cancer. Co-clinical trials are needed to customize for clinical application and to define adequate read-out cut-off values.
\end{abstract}

Keywords: Ex vivo culture, Colorectal liver metastases, CRLM, Predictive biomarker, Predictive test system

\section{Background}

Patients with colorectal carcinoma often develop metastases, foremost in the liver [1, 2]. Modern systemic therapeutic strategies include not only platinum-based chemotherapeutics (e.g. FOLFOX), but also novel targeted agents that are directed against a specific characteristic unique to the tumor cells (e.g. antibodies against Epidermal Growth Factor

\footnotetext{
* Correspondence: steve.martin@charite.de

${ }^{1}$ Institute of Pathology, University Medical Center Mainz, Langenbeckstraße 1, 55131 Mainz, Germany

${ }^{2}$ Institute of Pathology, Charité - Universitätsmedizin Berlin, corporate

member of Freie Universität Berlin, Humboldt-Universität zu Berlin and Berlin

Institute of Health, Campus Charité Mitte, 10117 Berlin, Germany

Full list of author information is available at the end of the article
}

receptor or Programmed cell death ligand 1). Despite numerous promising new drugs, response rates are relatively low, rendering the prognosis of metastasized colorectal carcinoma still unfavourable [2-6]. Adequate stratification is of the utmost importance to select those patients that show a clinical benefit outweighing the side effects of treatment and justifying high costs. Nowadays, this is performed using extensive molecular profiling to identify predictive biomarkers, but clinical practice shows that response to therapy cannot always be reliably predicted using this approach. So far, very few predictive molecular biomarkers have been identified in the context of colorectal carcinoma, the most prominent of which are mutations of KRAS and NRAS that cause

(C) The Author(s). 2019 Open Access This article is distributed under the terms of the Creative Commons Attribution 4.0 International License (http://creativecommons.org/licenses/by/4.0/), which permits unrestricted use, distribution, and 
irresponsiveness to anti-EGFR antibodies (e.g. Cetuximab) [7-10]. Other factors such as the tumor-stromal interaction; the specific immune landscape and epigenetic factors seem to play a major role in defining its biological behavior that cannot be predicted with molecular profiling alone [11, 12]. A promising technique to overcome this predicament is to measure therapeutic response using an ex vivo functional assay that cultivates a viable sample of the tumor itself. Various 2D monolayer and 3D models have been proposed and their advantages and disadvantages have been compared in a recent review [13]. The tissue slice culture approach shows the best comparability with the original tumor - preserving tumor morphology and microenvironment - while showing a high experimental success rate as well as a short generation time. Here, the non-fixed viable tumor is cut into thin slices and cultured directly for several days. Recently, few research groups have shown that the functional assessment of primary colorectal carcinoma tissue is feasible using this innovative technique [14-16]. However, stratifying patients with metastatic disease into optimal therapy-regiments requires sampling and cultivation of the metastatic tumor tissue.

In this study, we describe a protocol for optimal tissue slice culture of hepatic metastases of colorectal carcinoma and propose an automated, easy to use and objective readout strategy for measuring susceptibility to Oxaliplatin, Cetuximab and Pembrolizumab.

\section{Methods}

\section{Patients}

Nine hepatic metastasectomy specimens of colorectal carcinoma were included in this study. The patients were treated at the Department of General Visceral and Transplantation Surgery of the University Medical Center Mainz between 2017 and 2018. The study was approved by our institution's ethics committee. Table 1 depicts the patient's clinical characteristics.

\section{Tissue slice culture system}

Immediately after surgery, the metastasectomy specimens were transported to the Institute of pathology. Viable tissue (length: $10 \mathrm{~mm}$; diameter: $6 \mathrm{~mm}$ ) from the invasive margin of the metastasis was sampled using a punch tool (KAI Medical Biopsy Punch, Solingen, Germany) and stored in $4{ }^{\circ} \mathrm{C}$ chilled Krebs-Henseleit-Buffer (Sigma-Aldrich/Merck, Darmstadt, Germany). In order to confirm the extraction of adequate tumor tissue, a $1 \mathrm{~mm}$ disc was removed with a scalpel from one end of the punch and evaluated in frozen section by a pathologist. Samples without viable tumor were discarded. Punches were then aligned, mounted and immobilized using an agar-ring and cut into thin homogenous slices of $300 \mu \mathrm{m}$ thickness using a Vibratome VT1200 (Leica Microsystems). They were collected in $4{ }^{\circ} \mathrm{C}$ chilled Krebs-Henseleit-Buffer and randomized before distribution to control and therapy groups. The vibration amplitude was adjusted according to the tissue consistency and set between 1 and $2.5 \mathrm{~mm}$. The cutting-velocity was set to $0.4 \mathrm{~mm} / \mathrm{s}$. Tissue slices were cultured on special cellculture inserts (PET membrane with $0.4 \mu \mathrm{m}$ pore size, Falcon, Corning, USA) to allow preservation of the 3dimensional structure and assuring the supply with oxygen and cell medium. DMEM (ATCC, Manassas, USA) cell culture medium supplemented with 1\% Penicillin/Streptomycin (Sigma-Aldrich/Merck, Darmstadt, Germany; 10000 U Penicillin $+10 \mathrm{mg} / \mathrm{ml}$ Streptomycin in $0.9 \% \mathrm{NaCl}$ ) and 10\% Fetal Calf Serum (Sigma-Aldrich/Merck, Darmstadt, Germany) was used. For additional oxygen supply, plates were put on an orbital shaker (Thermo Scientific, MaxQ2000 $\mathrm{CO}_{2}$ Plus, $55 \mathrm{rpm}$ ) during incubation. Incubation was performed at $37^{\circ} \mathrm{C}$ under atmospheric oxygen and $\mathrm{CO}_{2}$ levels. Medium (with or without systemic agents) was changed after 1 hour and every additional $24 \mathrm{~h}$. After $72 \mathrm{~h}$ of incubation, tissue slices were harvested and fixed in $4 \%$ buffered formalin for a maximum of $24 \mathrm{~h}$. The time between the end of surgery and the start of cultivation of the tumor tissue slices should be as low as possible and was in our case minimally $2 \mathrm{~h}$ and maximally $4 \mathrm{~h}$ (median $3 \mathrm{~h}$ ).

\section{Treatment regimen}

Tissue slices were treated with two concentrations of Oxaliplatin (5 and $20 \mu \mathrm{M})$; Cetuximab (20 and $200 \mathrm{nM}$ ) and Pembrolizumab (140 and $1400 \mathrm{nM}$ ). Concentrations were chosen based on already published cell-culture experiments and recent clinical trials [16-20]. In order to account for tumor-heterogeneity, cultivation was performed in quadruplets $(n=4)$ for each drug and concentration. Twelve tissue slices $(n=12)$ were used for the untreated control group. Due to the small size of the liver metastasis, only triplicates were used in case of patients 9 and 4, respectively.

\section{Conventional and immunohistochemical staining}

Tissue slices were paraffin embedded and processed to $2 \mu \mathrm{m}$ sections by a microtome for morphological and immunohistochemical evaluation. For morphological analyses, sections were stained with Hematoxylin and eosin (H\&E) and with Elastika-van-Gieson (EvG) according to manufacturer specifications (Roth, Karlsruhe, Germany). Proliferation activity was evaluated using the immunohistochemical surrogate marker Ki-67. Apoptotic indices were assessed using cleaved Caspase 3 (Casp 3) immunostaining. In addition, key-proteins of the checkpoint inhibition system PD1 and PD-L1 were stained on whole slides of the routine-diagnostic sections. Furthermore, microsatellite stability was evaluated using immunohistochemical evaluation of MLH1 and MSH2. Prior to immunostaining sections were dewaxed $\left(30 \mathrm{~min}\right.$ at $60^{\circ} \mathrm{C} ; 3 \times 5 \mathrm{~min}$ Xylol) and rehydrated (decreasing alcohol concentration 100 to 50\% Ethanol, each $3 \mathrm{~min}$ ). Staining was performed automatically using the Dako EnVision ${ }^{\text {TM }}$ FLEX HRP/DAB; K 8010 Kit 
Table 1 Patient characteristics

\begin{tabular}{|c|c|c|c|c|c|c|c|c|c|}
\hline & Patient 1 & Patient 2 & Patient 3 & Patient 4 & $\begin{array}{l}\text { Patient } \\
5\end{array}$ & $\begin{array}{l}\text { Patient } \\
6\end{array}$ & Patient 7 & Patient 8 & Patient 9 \\
\hline Initial Diagnosis & June 2018 & $\begin{array}{l}\text { March } \\
2014\end{array}$ & July 2017 & $\begin{array}{l}\text { February } \\
2017\end{array}$ & $\begin{array}{l}\text { May } \\
2017\end{array}$ & $\begin{array}{l}\text { June } \\
2016\end{array}$ & May 2013 & March 2013 & $\begin{array}{l}\text { August } \\
2016\end{array}$ \\
\hline \multicolumn{10}{|l|}{ Primary } \\
\hline localization & rectum & rectum & rectum & rectum & caecum & rectum & rectum & rectum & CUP/iCRC \\
\hline date resection & June 2019 & Mar 2014 & Oct 2017 & June 2017 & $\begin{array}{l}\text { May } \\
2017\end{array}$ & $\begin{array}{l}\text { Nov } \\
2016\end{array}$ & June 2013 & Mar 2013 & n.a. \\
\hline pTNM & $\begin{array}{l}\text { pT3 pN1b } \\
\text { pM1a (HEP) }\end{array}$ & $\begin{array}{l}\text { ypT2 pNo } \\
\text { cM0 }\end{array}$ & $\begin{array}{l}\text { ypT3 } \\
\text { pNO } \\
\text { cM0 }\end{array}$ & $\begin{array}{l}\text { ypT2 } \\
\text { ypN1a } \\
\text { cM0 }\end{array}$ & $\begin{array}{l}\text { pT3 } \\
\text { pN1a } \\
\text { cM0 }\end{array}$ & $\begin{array}{l}\text { ypT4b } \\
\text { ypN1b } \\
\text { cM0 }\end{array}$ & $\begin{array}{l}\text { pT4b } \\
\text { pN1a } \\
\text { pM1a(HEP) }\end{array}$ & $\begin{array}{l}\text { pT3 } \\
\text { pNO } \\
\text { cM0 }\end{array}$ & n.a. \\
\hline LN/Pn & L1, V1, Pno, & LO, Vo, PnO & LO, Vo, PnO & LO, VO, PnO & $\begin{array}{l}\text { Lo, V1, } \\
\text { Pno }\end{array}$ & $\begin{array}{l}\mathrm{L1}, \mathrm{V} 1 \\
\mathrm{Pn} 1\end{array}$ & $\begin{array}{l}\text { V0, L1, } \\
\text { Pn1 }\end{array}$ & L1, V0, Pno & n.a. \\
\hline UICC-stage & IVA & । & $\|$ & $\| \mathrm{A}$ & $\| \mathrm{IIB}$ & IIIC & IVA & IVA & n.a. \\
\hline \multicolumn{10}{|l|}{ Hepatic Metastasis } \\
\hline date resection & Nov 2018 & May 2018 & July 2018 & Aug 2018 & $\begin{array}{l}\text { Aug } \\
2018\end{array}$ & $\begin{array}{l}\text { Sep } \\
2018\end{array}$ & Aug 2017 & Aug 2017 & July 2017 \\
\hline $\begin{array}{l}\text { synchronous - 0, } \\
\text { metachronous - } 1\end{array}$ & 0 & 1 & 1 & 1 & 1 & 1 & 0 & 1 & n.a. \\
\hline \multicolumn{10}{|l|}{ Molecular biology } \\
\hline KRAS & WT & $\begin{array}{l}\text { mutation } \\
\text { G12D }\end{array}$ & $\begin{array}{l}\text { mutation } \\
\text { G12A }\end{array}$ & $\begin{array}{l}\text { mutation } \\
\text { G13D }\end{array}$ & WT & WT & WT & WT & WT \\
\hline NRAS & WT & WT & WT & WT & WT & WT & WT & $\begin{array}{l}\text { mutation G13R } \\
\text { "c37G > C" }\end{array}$ & WT \\
\hline BRAF & WT & WT & WT & WT & WT & WT & WT & WT & WT \\
\hline MS-stability & MSS & MSS & MSS & MSS & MSS & MSS & MSS & MSS & MSS \\
\hline Systemic therapy* & yes & yes & yes & yes & no & yes & yes & no & yes \\
\hline \multicolumn{10}{|l|}{ Checkpoint Inhibition } \\
\hline PDL-1 IC\% & 50 & 23 & 13 & 21 & 16 & 25 & 5 & 6 & 51 \\
\hline PDL-1 TC\% & 0.1 & 0.5 & 0.1 & 2.5 & 0.5 & 0.2 & 0 & 0 & 2 \\
\hline PDL-1 CPS & 50.1 & 23.5 & 13.1 & 23.5 & 16.5 & 25.2 & 5 & 6 & 53 \\
\hline PD1 IC\% & 36 & 25 & 29 & 20 & 41 & 31 & 35 & 21 & 34 \\
\hline Death & no & no & no & no & no & no & no & no & no \\
\hline Recurrence ${ }^{* *}$ & Jan 2019 (PUL) & no & no & no & no & no & no & no & $\begin{array}{l}\text { Aug } 2017 \\
(\text { THO) } \\
\text { Feb 2018 } \\
\text { (OSS) } \\
\text { May } 2018 \\
\text { (HEP) }\end{array}$ \\
\hline
\end{tabular}

CUP/iCRC = Cancer of unknown Primary, immunophenotypically colorectal carcinoma; MS-stability = microsatellite stability; MSS = microsatellite stable, WT = wild type, Jan = January, Feb = February, Mar = March, Aug = August, Oct = October, Nov = November, THO = thorax, OSS = osseous, HEP = hepatic * details of systemic therapy in Additional file 2: Table S6), ${ }^{* *}$ recurrence after resection of analyzed hepatic metastasis

(Dako, Agilent, Santa Clara, USA) and the BenchMark ULTRA platform (Ventana Medical Systems, Oro Valley, USA) according to the manufacturer's specifications. All buffers and chemical agents were included in the kit. While the primary antibodies Ki-67 (Dako Ref.: IR626, mouse), MLH1 (Dako Ref.: IR079, mouse) and MSH2 (Dako Ref.: IR085, mouse) were ready to use, PD1 (Abcam, ab52587, mouse) was diluted 1:100, PD-L1 (Abcam, ab213524, rabbit) was diluted 1:250 and Casp 3 (Cell Signaling, Ref: $05 / 2017$, rabbit) was diluted 3:250. All sections were heated for $35 \mathrm{~min}$ in a steam cooker at pH 6 (citrate-buffer; Ki-67, PD1, PD-L1, Casp 3) or pH 9 (EDTA; MSH2, MLH1) for antigen retrieval.

\section{Analysis of RAS and BRAF- mutation}

For DNA extraction, an adequate paraffin block was selected by an experienced pathologist (DW). Up to 10 unstained sections (thickness: $5 \mu \mathrm{m}$ ) of each block were manually macrodissected to enrich tumor cells. Tumor cell content ranged from 50 to $80 \%$, with a median 
cellularity of $60 \%$. DNA was isolated using RSC DNA FFPE PLUS Custom Kit AX 4920 Promega (Wisconsin, USA) and quantified using Nano Drop (Avantor, Pennsylvania, USA). RAS mutations were analyzed using PCR-based Sanger sequencing. Following primers were used:

NRAS Gene Exon 2

- NRAS-F 5'-GATGTGGCTCGCCAATTAAC-3'

- NRAS-R 5'-CCGACAAGTGAGAGACAGGA-3'

- NRAS-RN 5'-GATCAGGTCAGCGGGCTA-3'

NRAS Gene Exon 3

- NRAS-F 5'-CCCCTTACCCTCCACACC-3'

- NRAS-R 5'-GAACACAAAGATCATCCT TTCAGA-3'

- NRAS-RN $5^{\prime}$-CCTTTCAGAGAAAATAATGCTC CT-3'

NRAS Gene Exon 4

- NRAS-F 5'-TGTTCTGATAATATATTCCCGT-3'

- NRAS-R 5'-GCACTCCAGCTTAGAAGATA-3'

- NRAS-RN 5'-GGATCACATCTCTACCAGAG-3'

KRAS Gene Exon 2

- KRAS-F 5'-GGTGAGTTTGTATTAAAAGGTA CTGG-3'

- KRAS-FN 5' -TTAACCTTATGTGTGACATGTT CTAA-3'

- KRAS-R 5'-GGTCCTGCACCAGTAATATGC-3'

- KRAS-RN 5'-AAAACAAGATTTACCTCTATTG TTGGA-3'

KRAS Gene Exon 3

- KRAS-F 5'-TCCAGACTGTGTTTCTCCCT-3'

- KRAS-R 5'-AACCCACCTATAATGGTGAATA TC-3'

- KRAS-RN 5'-TTTATGGCAAATACACAAAG AAAG-3'

KRAS Gene Exon 4

- KRAS-F 5'-TTTTTCTTTCCCAGAGAACAAAT-3'

- KRAS-R 5'-AGCATAATTGAGAGAAAAACTGA3'

- KRAS-RN 5'-ACATAACAGTTATGATTT TGCAG-3'

BRAF Gene Exon 15

- BRAF-F 5' - ATCTCTTACCTAAACTCTTCAT AATGC -3

- BRAF-R 5' - GGCCAAAAATTTAATCAGTGGA-3'

The sequencing results were interpreted using Genome Lab GeXP Genetic Analysis System (Beckman Coulter, California, USA).

\section{Analysis of tissue slice culture}

All sections were digitalized using the NanoZoomer-Series Digital Slide Scanner (40x, Hamamatsu Photonics, Hamamatsu, Japan). Firstly, H\&E stained untreated tissue slices (controls) were visually compared with their representative paraffin-embedded sections used in routine-diagnostic by a pathologist. Overall morphological appearance, architecture, growth-patterns, grading of differentiation and nuclear characteristics of the tumor were assessed. Secondly, untreated (control) and treated (Oxaliplatin, Cetuximab, Pembrolizumab) tissue slices were compared using an automated analysis-readout based on the Halo platform from Indica Labs (Corrales, NM, USA). For immunohistochemical analysis of Ki-67 the module CytoNuclear v1.4 was applied. In a training phase, five representative sections were used to define staining parameters (e.g. minimum nuclear optical density, minimum staining optical density, nuclear and cellular size and roundness) for an optimal distinction between Ki-67 positive and negative tumor cells. A tissue classifier was then trained separately for each section to select epithelial tumor cells. Stroma, blood vessels and areas of necrosis were excluded from analysis. The percentage of Ki-67positive tumor cells in relation to the total number of tumor cells was calculated and used as a surrogate marker for the proliferation activity. All automated results were visually validated for accuracy. For morphometrical analysis, the EvG stain was used. For each tumor tissue slice a Halo tissueclassifier was trained to recognize the stromal, tumor and necrosis compartment. The area of each compartment was calculated and normalized to the total analyzed area. The automated results were visually validated. For immunohistochemical analysis of Casp 3 digitized slides were visually assessed semiquantitatively by two experienced pathologist (SZM, WR). The apoptotic state is expressed as the tumorapoptotic fraction defined as the number of Casp 3 positive tumor cells divided by the total number of tumor cells. Importantly, dependent on the cells stage of apoptosis, Casp 3 stain can be nuclear or cytoplasmatic [21]. Stain of nonepithelial cells, necrosis or cell debris was excluded (see Additional file 1). Tissue slices that showed no tumor were excluded from analysis (7 slices of 312). Figure 1 depicts the experimental set up of the tissue slice culture system.

\section{Proteins of the checkpoint inhibition system}

Immunohistochemical PD-L1 and PD1 positivity was analyzed based on the urothelial carcinoma PD-L1 interpretation manual of Agilent [22]. In short, staining of the cellmembrane was classified as positive. Whole slides of the routine-diagnostic sections were assessed visually and positive immune cells and tumor cells were determined in areas comprising approximately 100,000 tumor cells. Necrosis and cell-debris were excluded. Combined positivity score (CPS), tumor cell score (TC\%) and immune cell score (IC\%) were defined as follows and are depicted in Table 1: 


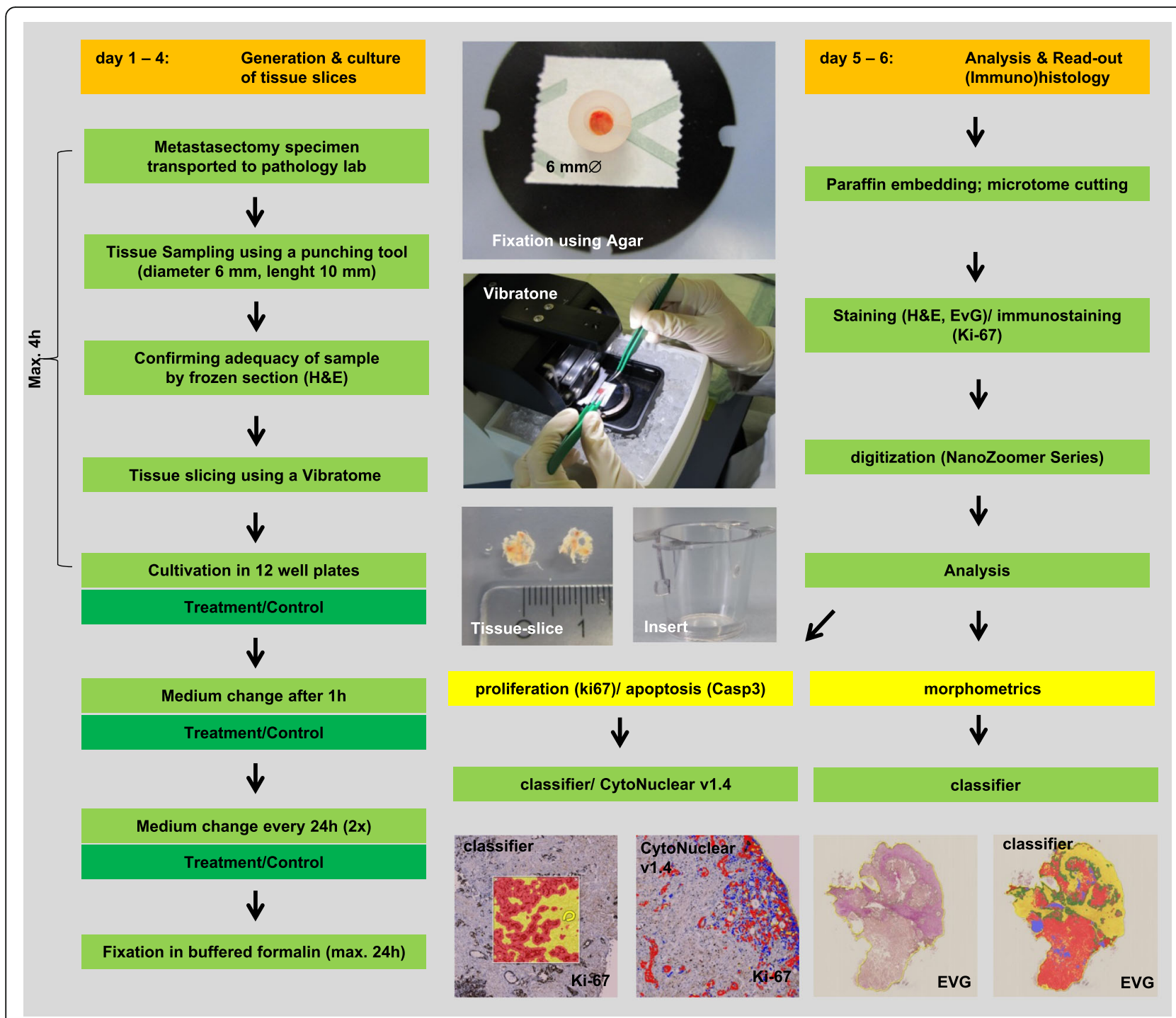

Fig. 1 Experimental setup of the tissue slice culture system. Susceptibility to systemic drugs is assessed within 6 days

$C P S=\frac{P D L-1 \text { positive tumor cells }+P D L-1 \text { positive immune cells }}{\text { total count of tumor cells }} \times 100$

$$
\begin{aligned}
& \text { TC\% }=\frac{P D L-1 \text { positive tumor cells }}{\text { total count of tumor cells }} \times 100 \\
& I C \%=\frac{P D L-1 \text { positive immune cells }}{\text { total count of tumor cells }} \times 100
\end{aligned}
$$

\section{Statistical analysis}

Analysis of morphometry, Ki-67-proliferation and Casp 3 apoptotic state was performed across all patients and for each patient individually. For the pooled analysis of the Ki-67-proliferation and Casp 3 apoptotic fraction and morphometry, the mean values of each patient were used and depicted in Box-Jitter plots. Statistical significant differences between the control and treatment groups were calculated using the nonparametric Mann-Whitney $U$ test. $P$-values $\leq 0.05$ were defined as significant. Additionally, the analysis was performed for each patient individually. To calculate differences between the control and treatment groups in each patient, the nonparametric Mann-Whitney $U$ test was performed. Wilcoxonsigned rank test for paired samples can only be used, if the number of tissue slices each group are equal in number. Since this requirement is not met in our study (treatment group $n=4$, control group $n=12$ ), the $p$-value of the Mann-Whitney $\mathrm{U}$ test gives the best approximation of statistical relevant group differences. For Ki-67-analysis, a representative $1 \mathrm{~mm}^{2}$ area of the routine-diagnostic section was included in the analysis. For the morphometrical analysis, the medians of the area of necrosis, tumor and stroma for each 
patient were depicted in stacked plots and normalized to the total area. For statistical analysis, the software Past Version 3.16 [23] was used.

\section{Results}

\section{Tissue slice culture}

The tumor tissue slice culture technique was adjusted for liver metastases of colorectal cancer patients. Tumor tissue from nine metastases was cultured for $72 \mathrm{~h}$ and morphologically compared to representative routine-diagnostic H\&E sections from the original tissue (see Fig. 2). There was a high morphological similarity between the ex vivo and in vivo tumor, as evidenced by comparable tumor growth-patterns, architecture, grading of differentiation and tumor cell cytology. The tumor of tissue slices exhibited only minimal heterogeneous nuclear changes like karyorrhexis, karyolysis or pyknosis in some tumor glands. The immunohistologically assessed proliferation activity (Ki-67) showed a moderate reduction in proliferation for tumors of patients 1, 2, 6, 7 and 9 and similar proliferation for tumors of patients 3 to 5 , when comparing the untreated tissue slices with a representative $1 \mathrm{~mm}^{2}$ area of the original tumor (see Fig. 3).

\section{Readout of proliferation index and apoptotic index}

The tumor tissue slice culture technique was used to measure drug responses of metastatic colorectal cancer tissue. Tumor tissue was treated with Oxaliplatin (5 and $20 \mu \mathrm{M})$, Pembrolizumab (140 and $1400 \mathrm{nM})$ and Cetuximab (20 and $200 \mathrm{nM}$ ) for $72 \mathrm{~h}$ and compared to untreated controls. To measure susceptibility to those drugs an automated analysis of the proliferation index using Ki-67 immunostain was performed for each patient individually (Fig. 3, Additional file 2: Table S1 and Additional file 3). Additionally semiquantitative analysis of the apoptotic index was carried out using Casp 3 immunostain (Fig. 4, Additional file 2: Table S2 and Additional file 3).

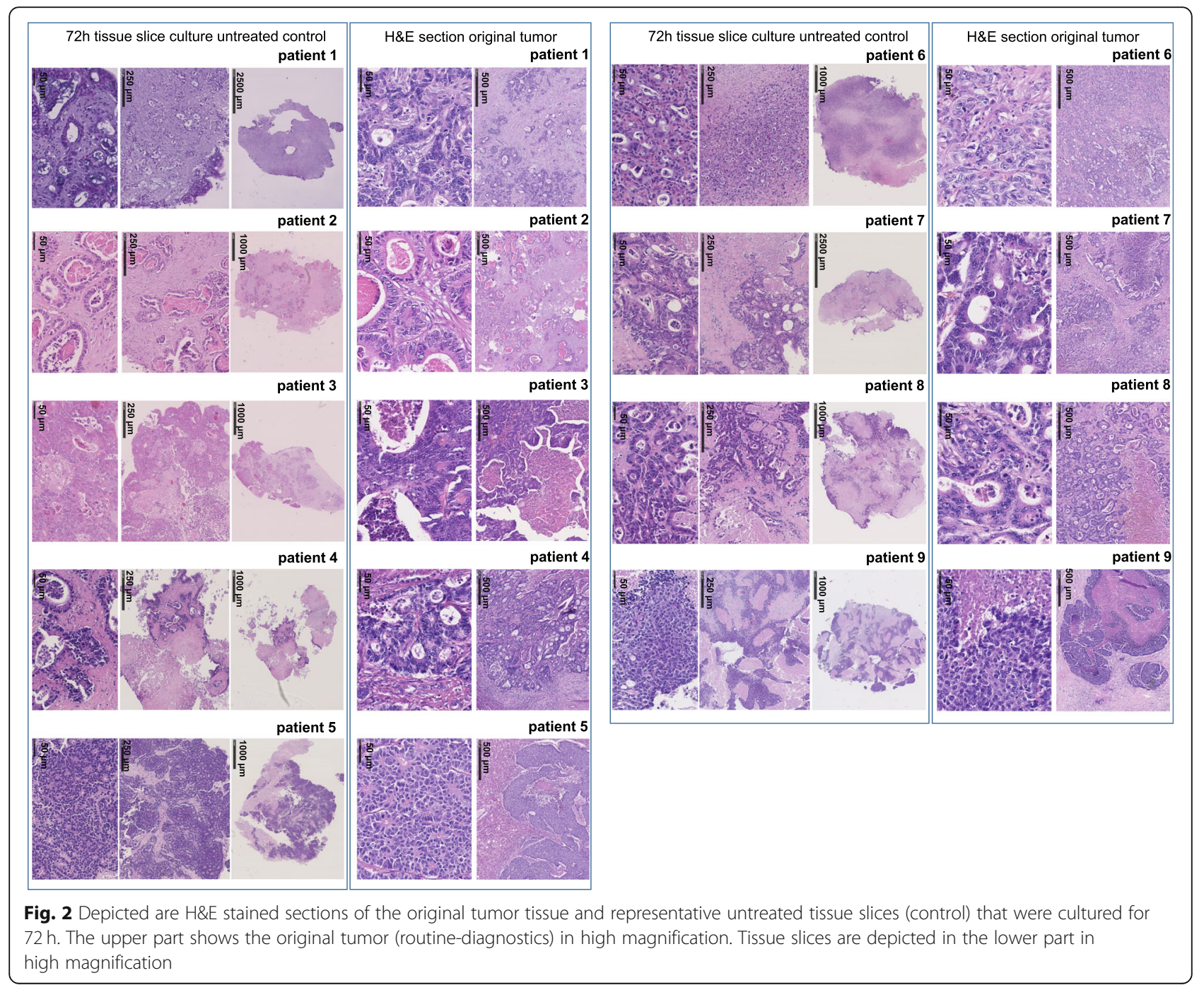




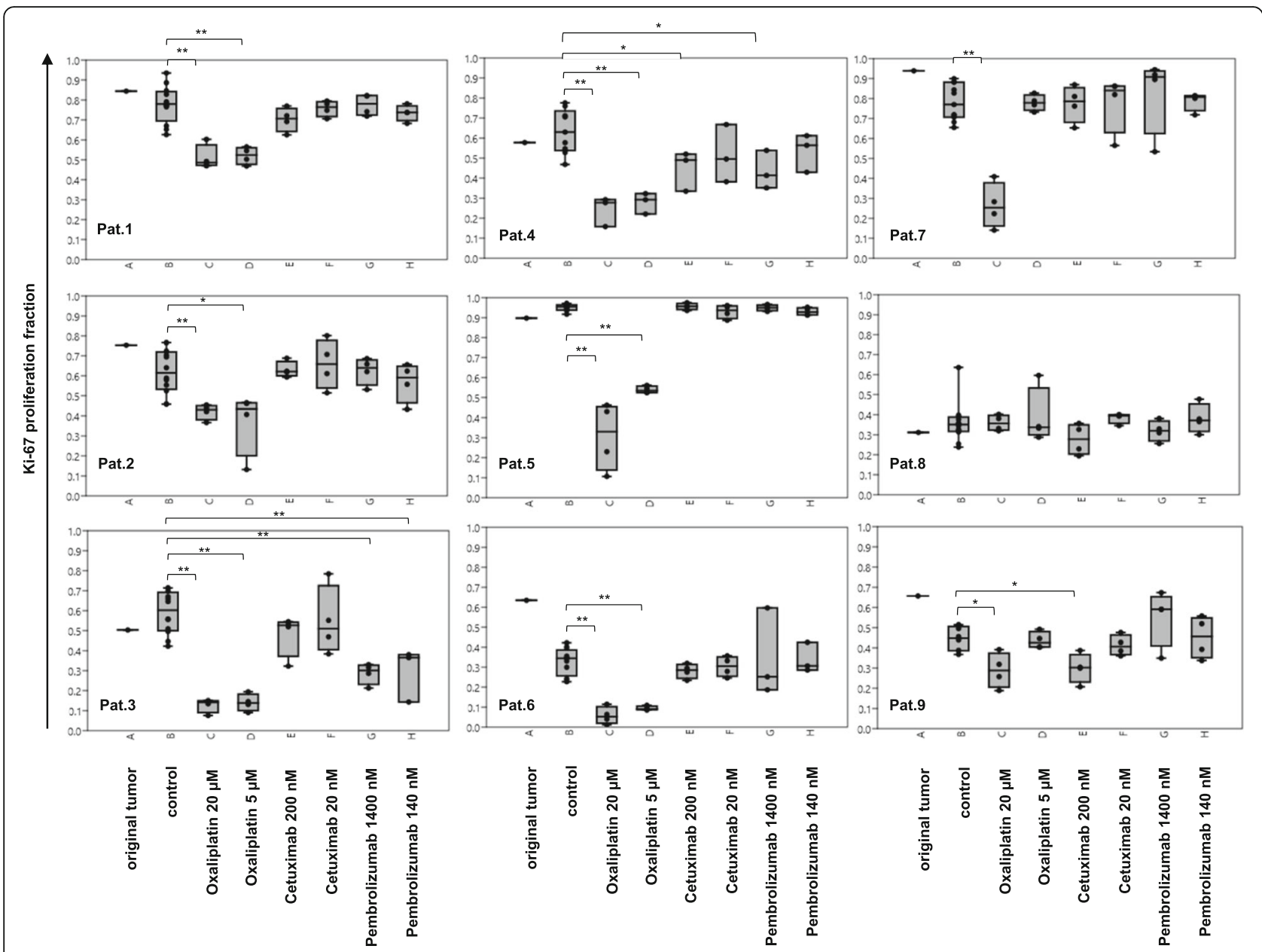

Fig. 3 Tumor- proliferative activity (Ki-67) of treated (Cetuximab, Pembrolizumab and Oxaliplatin) and untreated (control) tissue slices. Additionally, one $1 \mathrm{~mm}^{2}$ representative section of the original tumor tissue was included in the analysis (routine-diagnostic). The percentage of Ki67 positive tumor cells is depicted in Box-Jitter plots. Statistical differences were calculated using the Mann-Whitney $U$ test and are marked $\left({ }^{*} p\right.$ value $\leq 0.05 ;{ }^{* *} p$ value $\leq 0.01$ ). a- original tumor; b- control; c- Oxaliplatin $20 \mu \mathrm{M}$; d- Oxaliplatin $5 \mu \mathrm{M}$; e- Cetuximab $200 \mathrm{nM}$; f- Cetuximab 20 nM; g- Pembrolizumab $1400 \mathrm{nM}$; h- Pembrolizumab $140 \mathrm{nM}$

Proliferation activity of the untreated tissue slices were heterogeneous and varied between $95 \%$ in case 5 and $34 \%$ in case 6 (median value of $60 \pm 19 \%$ ). Regarding the original tumors proliferative activity ranged from $94 \%$ in case 7 to $31 \%$ in case 8 (median value of $65 \pm 19 \%$ ). Tumors of patients 1 to 6 showed a reduction of the Ki-67- positive tumor fraction when treated with $5 \mu \mathrm{M}$ and $20 \mu \mathrm{M}$ Oxaliplatin. Tumors of patients 7 and 9 showed a reduction only when treated with $20 \mu \mathrm{M}$ Oxaliplatin. A dosage dependent decrease of proliferation was visible for tumor of patient 5 (95\% control, $53 \% 5 \mu \mathrm{M}$ and $33 \% 20 \mu \mathrm{M}$ Oxaliplatin). The absolute difference of the medians between the untreated (control) and treated $(20 \mu \mathrm{M}$ Oxaliplatin) group was ranging from $62 \%$ (patient 5) to $16 \%$ (cases 2 and 9 ) or $0 \%$ (case 8 ). Only tumors of patients 3,4 and 9 showed a reduction in proliferation, when treated with Pembrolizumab or Cetuximab. Tissue of patient 3 showed a median drop of 23 and 30\% when treated with Pembrolizumab (140 and $1400 \mathrm{nM}$ respectively), which was smaller compared to the Oxaliplatin treatment ( $46 \%$ for both concentrations). Tumor of patient 4 showed a decrease in Ki-67 positivity when treated with $200 \mathrm{nM}$ Cetuximab (14\%) or $1400 \mathrm{nM}$ Pembrolizumab (22\%). Again, this reduction was lower than in the Oxaliplatin-treated group (drop of $35 \%$ for both concentrations). Tumor of patient 9 showed a median reduction of the proliferation index of $15 \%$, when treated with $200 \mathrm{nM}$ Cetuximab, which was as high, as in the Oxaliplatin-treated group. Tumor of patient 8 showed no differences in proliferation between control and treatment groups. The tumor-apoptotic fraction of the untreated tissue slices were also heterogeneous and varied between 1\% (case 2) and $9.5 \%$ (case 7). Tumors of patients 4 to 5 showed an increase of the Casp 3- positive tumor fraction 


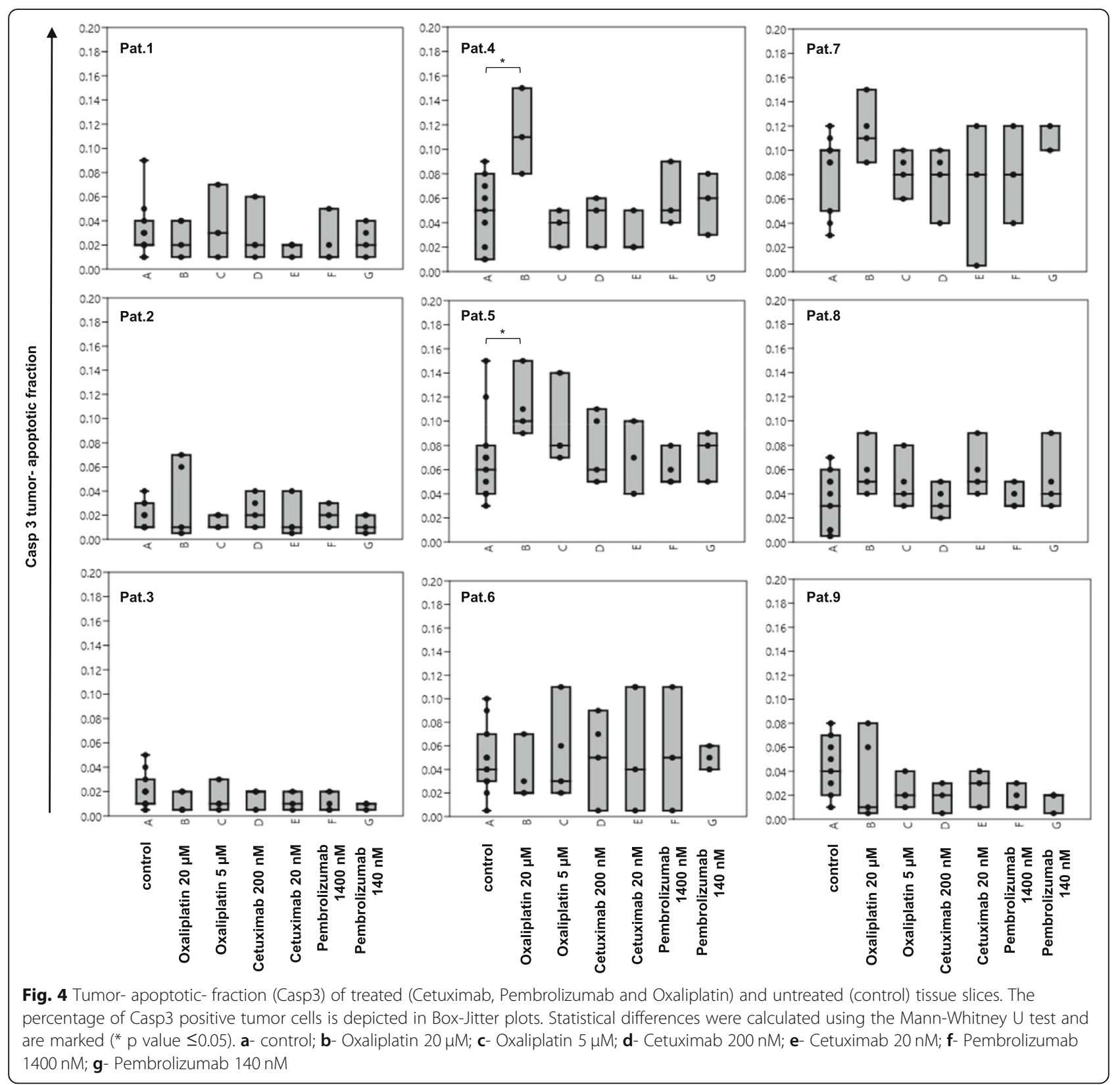

when treated with $20 \mu \mathrm{M}$ Oxaliplatin. All other treatment groups showed no statistically relevant differences compared to the control group.

Pooled analysis of the Ki-67 proliferation fraction across all nine cases confirmed a statistical significant and dosage dependent reduction when treated with Oxaliplatin. There were no significant differences in proliferation after treatment with Pembrolizumab or Cetuximab. Pooled analysis of the Casp 3 tumorapoptotic fraction across all nine cases revealed no statistical significant differences between control and treatment groups (see Fig. 5).

\section{Automated readout of morphometrical analysis}

In addition to the evaluation of proliferative changes after drug treatment, also morphometric changes were assessed. To measure variations of the area of necrosis, stroma and tumor, treated and untreated tissue slices were stained with EvG and quantified using the Haloplatform. In contrast to H\&E, EvG showed a superior contrast between necrosis and stroma in direct comparison and led to a more accurate distinction using the Halo classifier (data not shown). Findings of the analysis are depicted in Fig. 6 and Additional file 2: Table S3). The morphometric analysis of the untreated tissue slices 

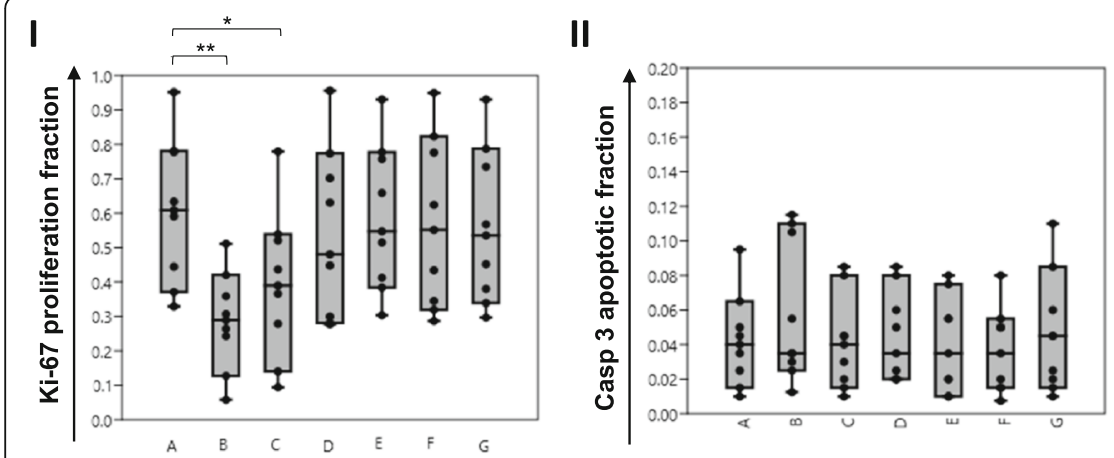

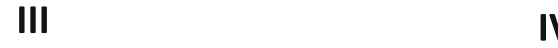

IV

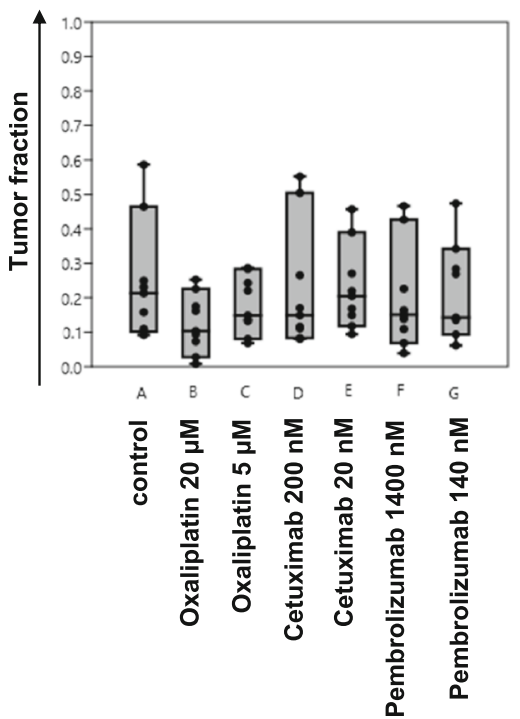

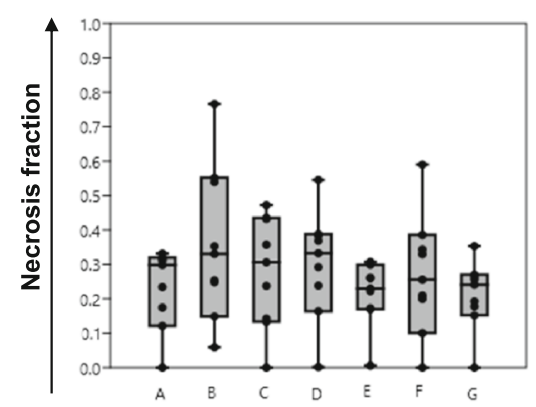

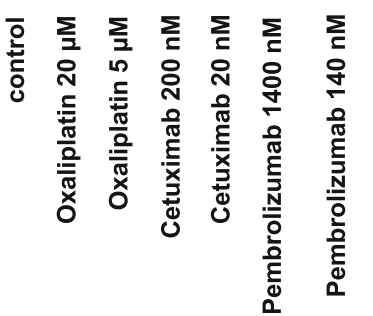

V
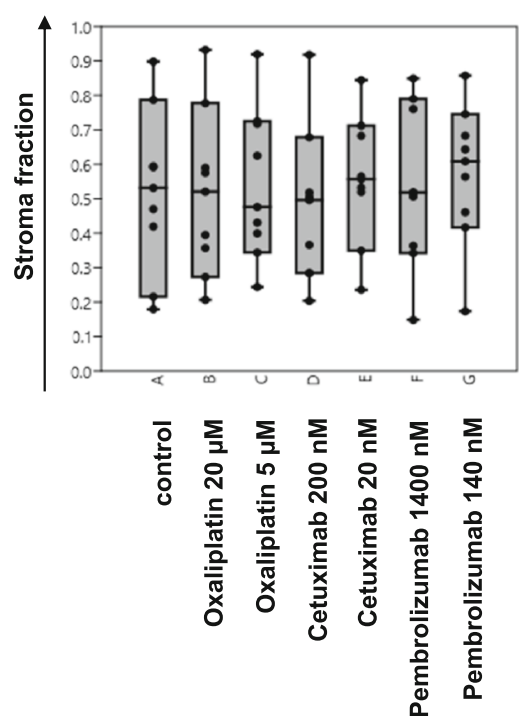

Fig. 5 Depicted are tumor-proliferative fractions (I), tumor-apoptotic fractions (II), tumor (III), necrosis (IV) and stroma (V) fractions of Ki-67, Casp3 and morphometric analysis across all nine patients in Box-Jitter plots. The mean-values of each patient are depicted as a black dot. Statistical differences were calculated using the Mann-Whitney $\mathrm{U}$ test and are marked ( ${ }^{*} \mathrm{p}$ value $\leq 0.05 ;{ }^{* *} \mathrm{p}$ value $\left.\leq 0.01\right)$. a- control; b- 0 xaliplatin $20 \mu \mathrm{M}$; cOxaliplatin 5 HM; d- Cetuximab 200 nM; e- Cetuximab 20 nM; f- Pembrolizumab 1400 nM; g- Pembrolizumab 140 nM

showed substantial differences in the distribution of necrosis, tumor and stroma for all 9 cases. While tumor of patient 3 showed the highest amount of necrosis (median 37\%), tumor of patient 9 showed no necrosis at all. An increase in necrosis accompanied by a reduction of the tumor area was visible for cases 5 and 9 when treated with $20 \mu \mathrm{M}$ Oxaliplatin and for case 7 when treated with 5 and $20 \mu \mathrm{M}$ Oxaliplatin. Tumors of patients 1 and 6 showed an increase in necrosis after treatment with $200 \mathrm{nM}$ Cetuximab, in case of patient 6 accompanied by a reduction of the stromal compartment. Tumor of patient 4 showed an increase in necrosis when treated with $1400 \mathrm{nM}$ Pembrolizumab. Tumor of patient 3 showed no differences among the groups. Tumors of patients 2 (Pembrolizumab), 5 (Cetuximab) and 8 (Oxaliplatin, Cetuximab and Pembrolizumab) showed a reduction of areas of necrosis, in case of patient 8 accompanied by an increase of the stromal compartment (Pembrolizumab). Pooled morphometric analysis across all nine cases showed no statistically significant differences in necrosis, stroma or tumor-area between control and treatment groups (see Fig. 5).

\section{Associations between drug response and molecular tumor characteristics}

In order to determine associations of therapy response with molecular tumor characteristics, the RAS mutation status as well as the immunohistochemical evaluation of microsatellite stability and checkpoint protein expression was assessed.

Visual semiquantitative analysis in whole slides of the original tumor sections showed moderate to high infiltrates of PD1 positive tumor-associated immune cells for all cases particularly at the invasive margin. The PD1 immune cell score (IC\%) ranged from 20 to 36 (see Table 1 and Additional file 2: Table S4). PD-L1 analysis showed only few positive tumor cells and moderate to high infiltrates of PD-L1 positive tumor-associated immune cells, particularly 


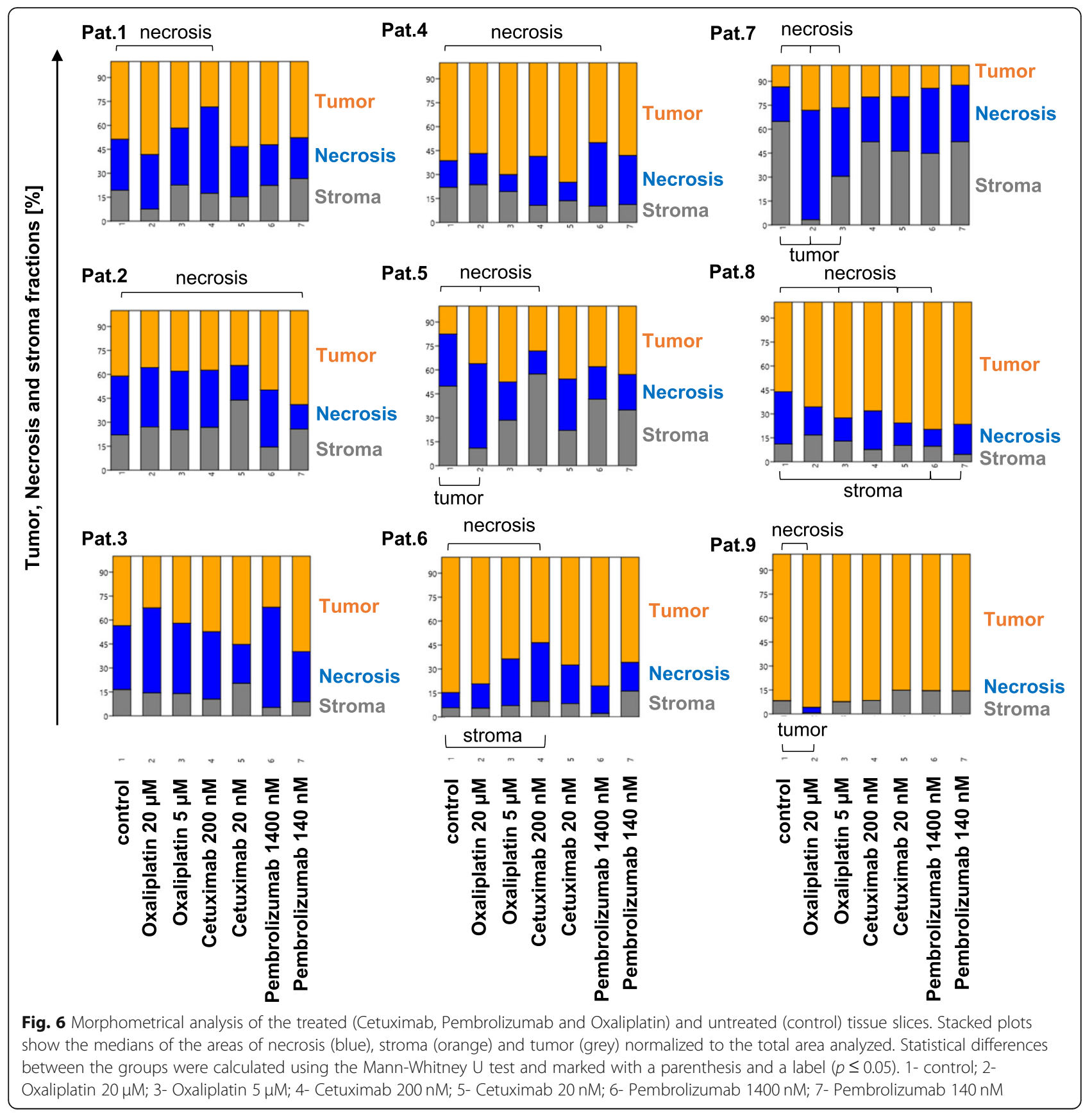

at the invasive margin. Only tumors of patients 4 and 9 showed a tumor cell score (TC\%) above 1. CPS scores were above 10 for the cases 1-6 and 9 and below 10 for the cases 7 and 8 (see Table 1 and Additional file 2: Table S5). Of all cases, only tumor tissue of patients 3 and 4 showed a reduction of proliferation when treated with Pembrolizumab.

All cases showed immunohistochemical expression of MLH1 and MSH2 and therefore no sign of microsatellite instability.

PCR-based Sanger sequencing showed KRAS mutations in metastatic tumor tissue of patients 2 (G12D), 3
(G12A) and 4 (G13D) and a NRAS mutation for patient 8 (G13R "c37G $>$ C). Of the five cases harboring no RAS-mutations, only tumor tissue of patient 9 showed a reduction of proliferative activity after treatment with Cetuximab. Additionally, tumor tissue of patient 4, harboring a G13D KRAS mutation, showed a response after cultivation with Cetuximab.

\section{Discussion}

In this study, we present an experimental ex vivo test system based on the tissue slice culture approach to 
estimate the susceptibility of colorectal liver metastases to different drugs. The tissue slice culture approach allows for cultivating tumor tissue, while preserving the tumor morphology and microenvironment. Keeping stromal-tumor interactions intact is fundamental, because they are known to affect progression, proliferation and sensitivity to drugs $[24,25]$. Since every tumor entity carries its own stromal-tumor microenvironment, optimal tissue slice culture protocols must be identified for each type separately. So far, only the tissue of the primaries of breast, prostate, lung, colorectal, gastroesophageal and head- and neck carcinomas have been successfully cultured for several days [16, 26-32]. Hepatic colorectal metastasectomy specimens are a major challenge for the tissue slice culture technique, since they show extensive regressive changes. This study is the first to successfully cultivate colorectal liver metastatic tissue for up to $72 \mathrm{~h}$, keeping stromal-tumor interactions intact and preserving the in vivo tumor morphology (for details of cultivation protocol see Methods and Additional file 4). Additionally, analysis of the proliferation activity showed only moderate if any differences between the in vivo (original tumor) and ex vivo (tissue slice) tumor. Although the technical, organizational and personnel requirements of the method will probably surpass the capabilities of some pathological institutes, implementation at larger and specialized university centers is easily possible.

The construction of a predictive ex vivo test system requires an objective and easy to use read out strategy. In this study, we used an automated analysis tool based on digital image analysis. Changes in proliferative activity of the tumor cells were measured using Ki-67-immunostaining as a surrogate marker. Median values were $60 \pm 19 \%$ for untreated tissue slices and $65 \pm 19 \%$ for original tumors, as was reported before [33, 34]. Changes in the tumorstroma-necrosis make-up of the tissue slices were measured using EvG-stains. Halo classifiers had to be trained for each section and the analysis visually validated by a pathologist (SZM) to be repeated if necessary. This automated procedure took about $5 \mathrm{~min}$ per section and is approximately as time-consuming as a purely visually semi-quantitative method. The essential advantages, however, are a reliable absolute quantification of the entire section in a short period of time and a high objectivity and reproducibility of the procedure.

Tumor tissue slices were treated with Oxaliplatin, Pembrolizumab and Cetuximab, all of which play an important role in the treatment of metastatic colorectal cancer. Oxaliplatin is a cytostatic drug that interlinks DNA-strands inhibiting replication [35] and represents in combination with fluorouracil and leucovorin the first-line standard therapy for metastatic colorectal carcinoma [36]. As a single agent, it demonstrates modest activity with response rates of 10 to $25 \%$ [37-40], which was confirmed in our study. All but one patients showed a dose-dependent reduction of the proliferative activity that was additionally confirmed in a pooled analysis across all nine patients. The morphometric analysis showed increases in areas of necrosis for cases 5, 7 and 9, which was partially accompanied by a decrease in the tumor area.

Cetuximab is a monoclonal antibody against the epidermal growth factor receptor EGFR and is often added to first line therapy to improve outcome [4, 10, 41]. It exerts its biological anti-tumor effects in two ways. On the one hand, the EGFR signaling pathway on tumor cells is specifically blocked, leading to cell cycle arrest, reduction of tumor-cell proliferation and increase of apoptosis [42]. Therefore, mutations in the RAS gene are predictive for treatment failure. Of the five cases harboring no RASmutations in our study, only tumor of patient 9 seemed to be sensitive towards Cetuximab. Possible reasons for treatment resistance in those other patients are mutations of genes downstream the EGFR/RAS signaling cascade that are, although recommended, not regularly evaluated before systemic therapy in clinical practice [43]. This supports that molecular profiling alone cannot always accurately predict response to therapy in a clinical setting and underlines the need of additional predictive test systems. The tumor of patient 4 is the only one that harbored a RAS mutation while showing intermediate reduction of the proliferative activity after treatment with Cetuximab. However, this specific G13D mutation in the KRAS-gene was shown to be sensitive to Cetuximab treatment in a retrospective trial $[44,45]$ and in in-vitro cell-culture [46]. On the other hand, being an IgG1 antibody, Cetuximab can crosslink with and activate immune cells via its constant $(\mathrm{Fc})$ region to induce antibody-dependent cellular cytotoxicity (ADCC) [47, 48]. While tumor tissue slices are thought to preserve the immune compartment of local native immune cells during the cultivation process, the suitability of this technique to study ADCC effects has not been investigated so far and exceeded the scope of this study.

Pembrolizumab is a monoclonal antibody to programmed cell death 1 protein and FDA approved as second-line therapy for unresectable metastatic colorectal cancer that has high microsatellite instability or deficient mismatch repair [49-53]. Recent data supports that tumors harboring other mutations of DNA proofreading enzymes (e.g. POLE) also upregulate expression of immune checkpoints and are eligible to checkpoint inhibition, while showing an MSS Immunophenotype [52, 53]. Those mutations might explain the reduction of proliferation of tumors of patients 3 and 4 when treated with Pembrolizumab. However, only patient 4 showed a high PD-L1 TC\% score above 1. Whether PD-L1 immunostaining is indeed predictive for response to 
Pembrolizumab therapy in colorectal carcinoma is still unknown and needs to be evaluated in adequate prospective trials [51].

The apoptotic state of the tumor tissue was revealed using Casp 3 immunostain, which is a well-known and highly sensitive method to visualize different steps of the apoptotic process [21]. A significant increase in the number of apoptosis of tumor cells was only detected for tumor tissue of patients 4 and 5 , when treated with the cytotoxic drug Oxaliplatin, but was not confirmed in pooled analysis. This finding is supported by recent data of Buzzelli et al. who established colorectal cancer liver metastases organoids and observed that while organoids showed growth delay in response to Oxaliplatin treatment, they did not undergo significant cell death [54]. Both, this finding and our data suggest that Oxaliplatin limits tumor growth through reduction of proliferation and not by inducing apoptosis, which is consistent with its known function to inhibit DNA synthesis. Treatment of tumor tissue with Cetuximab and Pembrolizumab did not reveal a significant increase in the tumor-apoptotic fraction in this study. While there is no data available for colorectal cancer tissue, Gerlach et al. did also not detect significant changes in the number of Casp 3 positive cells after treatment of Head and Neck carcinoma tissue slices with Cetuximab [32].

In summary, the findings of this study suggest a direct correlation between the reduction of the proliferative tumor fraction and the level of drug sensitivity. Therefore, the tumor tissue slice culture approach seems feasible for measuring drug-responses and should be evaluated in further co-clinical trials. Here, a tumor tissue sample is processed in tissue slice culture before systemic therapy, allowing for subsequent direct comparison of ex vivo and in- vivo determined response rates.

There are several limitations to this study. Firstly, Oxaliplatin was used as a single agent rather than in combination with 5-FU. Also, only nine patients have been enrolled and investigated that were heterogeneous in their clinical characteristics regarding presurgical therapy, stage and localization of the primary tumor. In addition, there was no data available about the in vivo response rates to systemic therapy, as would be necessary for a co-clinical trial design. Furthermore, we have only performed an automated analysis of changes in morphometrics and proliferative activity via Ki-67. Since Casp 3 immunostain localization can be either cytoplasmatic or nuclear, depending on the apoptotic stage of the individual tumor cell, automated analysis was not possible, because all available digital modules rely on a sole nuclear or cytoplasmatic/ membranous localization of the immune stain. Therefore, evaluation was performed semiquantitatively by two experienced pathologists.

\section{Conclusion}

We showed that the tissue slice culture technology is feasible for conserving tumor-stroma morphology of hepatic metastases of colorectal cancer. Easy to use automated analysis tools objectively measure absolute changes of proliferation and the distribution among necrosis-, tumorand stroma- compartments after treatment with systemic drugs. Therefore, this study indicates a potential value of this technique as a patient-specific test-system of targeted therapy in the context of metastatic colorectal carcinoma. Future co-clinical trials will test this hypothesis and define adequate cut-off values of the readout data.

\section{Supplementary information}

Supplementary information accompanies this paper at https://doi.org/10. 1186/s12885-019-6270-4.

\section{Additional file 1: Figure S1. Depicted are examples of selective} nuclear and cytoplasmatic location of Casp 3 immunostain of tumor cells (upper row), depending on the individual stage of apoptosis. The tumor apoptotic fraction is defined as Casp 3 positive tumor cells divided by the total number of tumor cells. Stain of non-epithelial cells or unspecific stain of cell debris and necrosis (middle row) were ignored. The lower left picture shows a section detail with three tumor cells positively stained for Casp 3 (black arrows) and unspecific stain (red arrows).

Additional file 2: Supplementary Tables. Description of data: Tables with raw data of immunohistochemical and morphometrical analysis as well as evaluation of PD1 and PD-L1 immunostain and details of systemic therapy.

Additional file 3: Figure S2. Depicted are H\&E, EvG, Ki-67 and Casp 3 stained sections of representative treated (Cetuximab, Pembrolizumab and Oxaliplatin) and untreated (control) tissue slices of patient 5. The upper row depicts H\&E stained sections, little boxes show a higher magnification to show nuclear detail. The middle row shows EvG-stained sections and Ki-67 immunostain. The lower row shows Casp 3 Immunostain, little boxes show a higher magnification to show nuclear detail.

Additional file 4: Adaptations to Tumor Tissue Slice Culture for Hepatic Colorectal Metastases. More detailed information of the protocol of tumor tissue slice culture is provided.

\section{Abbreviations}

ADCC: antibody-dependent cellular cytotoxicity; Casp 3: cleaved caspase-3; CT: Computed Tomography; CUP: Cancer of unknown Primary; DW: Daniel C. Wagner; EvG: Elastica van Gieson; F: Fluorouracil; FOL: Folinic Acid; H\&E: Hematoxylin and Eosin; MSI: Microsatellite instable; MSS: Microsatellite stable; OX: Oxaliplatin; PET-CT: Positron emission tomography-computed tomography; RECIST: Response Evaluation Criteria In Solid Tumors; SUV: Standardized Uptake Value; SZM: Steve Z. Martin; WR: Wilfried Roth; WT: Wild type

\section{Acknowledgements}

We want to thank Pimrapat Gebert of the Institute of biometry and clinical epidemiology of the Charité Universitätsmedizin Berlin for the competent statistical consultation of this study. Furthermore, tissue samples were provided by the tissue bank of the University Medical Center Mainz in accordance with the regulations of the tissue biobank and the approval of the ethics committee of University Medical Center Mainz. Special thanks to Erik Springer, Stefanie Zimmer, Antonietta Valentino, Silke Mitschke and Bonny Adami.

\section{Authors' contributions}

Conception and design: WR, SZM, HL. Administrative support: SZM, HL, DH, WR. Study materials and patient data: WR, HL, KT. Experiments: SZM, NH, DW. Data Analysis: SZM. Manuscript writing: SZM. All authors read and approved the final manuscript. 


\section{Funding}

This research did not receive any specific grant from funding agencies in the public, commercial, or not-for-profit sectors.

\section{Availability of data and materials}

All data generated or analyzed during this study are included in this published article and its supplementary information files, with the exception of data that would compromise the individual privacy of the patients.

\section{Ethics approval and consent to participate}

The study was approved by our institution's ethics committee (Joint Ethics Committee of the Faculty of Economics and Business Administration of Goethe University Frankfurt and the Gutenberg School of Management \& Economics of the Faculty of Law, Management and Economics of Johannes Gutenberg University Mainz; ethikkommission@wiwi.uni-frankfurt.de). Informed written consent was obtained from all participants of this study.

\section{Consent for publication}

Not applicable.

\section{Competing interests}

The authors declare that they have no competing interests.

\section{Author details}

'Institute of Pathology, University Medical Center Mainz, Langenbeckstraße 1, 55131 Mainz, Germany. Institute of Pathology, Charité - Universitätsmedizin Berlin, corporate member of Freie Universität Berlin, Humboldt-Universität zu Berlin and Berlin Institute of Health, Campus Charité Mitte, 10117 Berlin, Germany. ${ }^{3}$ Department of General Visceral and Transplantation Surgery, University Medical Center Mainz, Langenbeckstraße 1, 55131 Mainz, Germany.

Received: 11 July 2019 Accepted: 16 October 2019

Published online: 01 November 2019

\section{References}

1. Ferlay J, Soerjomataram I, Dikshit R, et al. Cancer incidence and mortality worldwide: sources, methods and major patterns in GLOBOCAN 2012. Int J Cancer. 2015;136:E359-86.

2. Siegel RL, Miller KD, Jemal A. Cancer statistics, 2019. CA Cancer J Clin. 2019; 69:7-34.

3. Van Cutsem E, Cervantes A, Adam R, et al. ESMO consensus guidelines for the management of patients with metastatic colorectal cancer. Ann Oncol. 2016;27:1386-422.

4. Van Cutsem E, Kohne $\mathrm{CH}$, Hitre E, et al. Cetuximab and chemotherapy as initial treatment for metastatic colorectal cancer. N Engl J Med. 2009; 360:1408-17.

5. Cunningham D, Humblet $Y$, Siena S, et al. Cetuximab monotherapy and cetuximab plus irinotecan in irinotecan-refractory metastatic colorectal cancer. N Engl J Med. 2004;351:337-45.

6. Siena S, Sartore-Bianchi A, Di Nicolantonio F, Balfour J, Bardelli A. Biomarkers predicting clinical outcome of epidermal growth factor receptor-targeted therapy in metastatic colorectal cancer. J Natl Cancer Inst. 2009;101:1308-24.

7. Douillard JY, Oliner KS, Siena S, et al. Panitumumab-FOLFOX4 treatment and RAS mutations in colorectal cancer. N Engl J Med. 2013;369:1023-34.

8. Van Cutsem E, Lenz HJ, Kohne CH, et al. Fluorouracil, leucovorin, and irinotecan plus cetuximab treatment and RAS mutations in colorectal cancer. J Clin Oncol. 2015;33:692-700.

9. Bokemeyer C, Kohne CH, Ciardiello F, et al. FOLFOX4 plus cetuximab treatment and RAS mutations in colorectal cancer. Eur J Cancer. 2015;51: 1243-52.

10. Guren $T K$, Thomsen M, Kure EH, et al. Cetuximab in treatment of metastatic colorectal cancer: final survival analyses and extended RAS data from the NORDIC-VII study. Br J Cancer. 2017;116:1271-8.

11. Marks DL, Olson RL, Fernandez-Zapico ME. Epigenetic control of the tumor microenvironment. Epigenomics. 2016;8:1671-87.

12. Alizadeh AA, Aranda V, Bardelli A, et al. Toward understanding and exploiting tumor heterogeneity. Nat Med. 2015;21:846-53.

13. Meijer TG, Naipal KA, Jager A, van Gent DC. Ex vivo tumor culture systems for functional drug testing and therapy response prediction. Future Sci OA. 2017:3:FSO190.
14. Vaira V, Fedele G, Pyne S, et al. Preclinical model of organotypic culture for pharmacodynamic profiling of human tumors. Proc Natl Acad Sci U S A. 2010;107:8352-6.

15. Majumder B, Baraneedharan U, Thiyagarajan S, et al. Predicting clinical response to anticancer drugs using an ex vivo platform that captures tumour heterogeneity. Nat Commun. 2015;6:6169.

16. Sonnichsen R, Hennig L, Blaschke V, et al. Individual susceptibility analysis using patient-derived slice cultures of colorectal carcinoma. Clin Colorectal Cancer. 2018;17:e189-99.

17. Chen N, Fang W, Lin Z, et al. KRAS mutation-induced upregulation of PD-L1 mediates immune escape in human lung adenocarcinoma. Cancer Immunol Immunother. 2017;66:1175-87.

18. Gargett T, Yu W, Dotti G, et al. GD2-specific CAR T cells undergo potent activation and deletion following antigen encounter but can be protected from activationinduced cell death by PD-1 blockade. Mol Ther. 2016:24:1135-49.

19. Tashiro $T$, Okuyama $H$, Endo $H$, et al. In vivo and ex vivo cetuximab sensitivity assay using three-dimensional primary culture system to stratify KRAS mutant colorectal cancer. PLoS One. 2017;12:e0174151.

20. Li C, Singh B, Graves-Deal R, et al. Three-dimensional culture system identifies a new mode of cetuximab resistance and disease-relevant genes in colorectal cancer. Proc Natl Acad Sci U S A. 2017:114:E2852-61.

21. Bressenot A, Marchal S, Bezdetnaya L, Garrier J, Guillemin F, Plenat F. Assessment of apoptosis by immunohistochemistry to active caspase-3, active caspase-7, or cleaved PARP in monolayer cells and spheroid and subcutaneous xenografts of human carcinoma. J Histochem Cytochem. 2009:57:289-300.

22. Carpinteria C. PD-L1 IHC 22C3 pharmDx [package insert]. Dako, Agilent Pathology Solutions. 2018. URL: https://www.agilent.com/cs/library/ usermanuals/public/29257_22c3_pharmDx_cervical_interpretation_manual_ us.pdf; Last visited: 10.04 .2019$.

23. Hammer $\varnothing$, Harper, DAT, \& Ryan, PD. PAST: Paleontological Statistics Software Package for Education and Data Analysis. . Palaeontologia Electronica. 2001;4

24. McMillin DW, Negri JM, Mitsiades CS. The role of tumour-stromal interactions in modifying drug response: challenges and opportunities. Nat Rev Drug Discov. 2013;12:217-28.

25. Romero-Lopez M, Trinh AL, Sobrino A, et al. Recapitulating the human tumor microenvironment: Colon tumor-derived extracellular matrix promotes angiogenesis and tumor cell growth. Biomaterials. 2017;116:118-29.

26. Naipal KA, Verkaik NS, Sanchez H, et al. Tumor slice culture system to assess drug response of primary breast cancer. BMC Cancer. 2016;16:78.

27. van der Kuip H, Murdter TE, Sonnenberg M, et al. Short term culture of breast cancer tissues to study the activity of the anticancer drug taxol in an intact tumor environment. BMC Cancer. 2006;6:86.

28. Davies EJ, Dong M, Gutekunst $\mathrm{M}$, et al. Capturing complex tumour biology in vitro: histological and molecular characterisation of precision cut slices. Sci Rep. 2015;5:17187.

29. Holliday DL, Moss MA, Pollock S, et al. The practicalities of using tissue slices as preclinical organotypic breast cancer models. J Clin Pathol. 2013;66:253-5.

30. Carranza-Torres IE, Guzman-Delgado NE, Coronado-Martinez C, et al. Organotypic culture of breast tumor explants as a multicellular system for the screening of natural compounds with antineoplastic potential. Biomed Res Int. 2015;2015:618021.

31. Koerfer J, Kallendrusch S, Merz F, et al. Organotypic slice cultures of human gastric and esophagogastric junction cancer. Cancer Med. 2016;5:1444-53.

32. Gerlach MM, Merz F, Wichmann G, et al. Slice cultures from head and neck squamous cell carcinoma: a novel test system for drug susceptibility and mechanisms of resistance. Br J Cancer. 2014:110:479-88.

33. Weber JC, Nakano H, Bachellier $\mathrm{P}$, et al. Is a proliferation index of cancer cells a reliable prognostic factor after hepatectomy in patients with colorectal liver metastases? Am J Surg. 2001;182:81-8.

34. Peeters CF, de Waal RM, Wobbes T, Westphal JR, Ruers TJ. Outgrowth of human liver metastases after resection of the primary colorectal tumor: a shift in the balance between apoptosis and proliferation. Int J Cancer. 2006; 119:1249-53.

35. Ehrsson $\mathrm{H}$, Wallin I, Yachnin J. Pharmacokinetics of oxaliplatin in humans. Med Oncol. 2002:19:261-5.

36. Comella P, Casaretti R, Sandomenico C, Avallone A, Franco L. Role of oxaliplatin in the treatment of colorectal cancer. Ther Clin Risk Manag. 2009; 5:229-38. 
37. Levi F, Perpoint B, Garufi C, et al. Oxaliplatin activity against metastatic colorectal cancer. A phase II study of 5-day continuous venous infusion at circadian rhythm modulated rate. Eur J Cancer. 1993;29A:1280-4.

38. Machover D, Diaz-Rubio E, de Gramont A, et al. Two consecutive phase II studies of oxaliplatin (L-OHP) for treatment of patients with advanced colorectal carcinoma who were resistant to previous treatment with fluoropyrimidines. Ann Oncol. 1996;7:95-8.

39. Diaz-Rubio E, Sastre J, Zaniboni A, et al. Oxaliplatin as single agent in previously untreated colorectal carcinoma patients: a phase II multicentric study. Ann Oncol. 1998;9:105-8.

40. Extra JM, Espie M, Calvo F, Ferme C, Mignot L, Marty M. Phase I study of oxaliplatin in patients with advanced cancer. Cancer Chemother Pharmacol. 1990;25:299-303.

41. Bokemeyer C, Bondarenko I, Makhson A, et al. Fluorouracil, leucovorin, and oxaliplatin with and without cetuximab in the first-line treatment of metastatic colorectal cancer. J Clin Oncol. 2009;27:663-71.

42. Mendelsohn J, Baselga J. Epidermal growth factor receptor targeting in cancer. Semin Oncol. 2006;33:369-85.

43. Lupini L, Bassi C, Mlcochova J, et al. Prediction of response to anti-EGFR antibody-based therapies by multigene sequencing in colorectal cancer patients. BMC Cancer. 2015;15:808.

44. De Roock W, Jonker DJ, Di Nicolantonio F, et al. Association of KRAS p.G13D mutation with outcome in patients with chemotherapy-refractory metastatic colorectal cancer treated with cetuximab. JAMA. 2010:304:1812-20.

45. Tejpar S, Celik I, Schlichting M, Sartorius U, Bokemeyer C, Van Cutsem E. Association of KRAS G13D tumor mutations with outcome in patients with metastatic colorectal cancer treated with first-line chemotherapy with or without cetuximab. J Clin Oncol. 2012;30:3570-7.

46. Kumar SS, Price TJ, Mohyieldin O, Borg M, Townsend A, Hardingham JE. KRAS G13D mutation and sensitivity to Cetuximab or Panitumumab in a colorectal Cancer cell line model. Gastrointest Cancer Res. 2014;7:23-6.

47. Iannello A, Ahmad A. Role of antibody-dependent cell-mediated cytotoxicity in the efficacy of therapeutic anti-cancer monoclonal antibodies. Cancer Metastasis Rev. 2005;24:487-99.

48. Strome SE, Sausville EA, Mann D. A mechanistic perspective of monoclonal antibodies in cancer therapy beyond target-related effects. Oncologist. 2007:12:1084-95.

49. Kalyan A, Kircher S, Shah H, Mulcahy M, Benson A. Updates on immunotherapy for colorectal cancer. J Gastrointest Oncol. 2018;9:160-9.

50. Brahmer JR, Drake CG, Wollner I, et al. Phase I study of single-agent antiprogrammed death-1 (MDX-1106) in refractory solid tumors: safety, clinical activity, pharmacodynamics, and immunologic correlates. J Clin Oncol. 2010; 28:3167-75.

51. Le DT, Uram JN, Wang H, et al. PD-1 blockade in tumors with mismatchrepair deficiency. N Engl J Med. 2015;372:2509-20.

52. Llosa NJ, Cruise M, Tam A, et al. The vigorous immune microenvironment of microsatellite instable colon cancer is balanced by multiple counter-inhibitory checkpoints. Cancer Discov. 2015:5:43-51.

53. Gong J, Wang C, Lee PP, Chu P, Fakih M. Response to PD-1 blockade in microsatellite stable metastatic colorectal Cancer harboring a POLE mutation. J Natl Compr Cancer Netw. 2017;15:142-7.

54. Buzzelli JN, Ouaret D, Brown G, Allen PD, Muschel RJ. Colorectal cancer liver metastases organoids retain characteristics of original tumor and acquire chemotherapy resistance. Stem Cell Res. 2018;27:109-20.

\section{Publisher's Note}

Springer Nature remains neutral with regard to jurisdictional claims in published maps and institutional affiliations.

Ready to submit your research? Choose BMC and benefit from:
- fast, convenient online submission
- thorough peer review by experienced researchers in your field
- rapid publication on acceptance
- support for research data, including large and complex data types
- gold Open Access which fosters wider collaboration and increased citations
- maximum visibility for your research: over 100M website views per year
At BMC, research is always in progress.
Learn more biomedcentral.com/submissions

